\title{
SIRT1 Expression Is Associated With Cell Proliferation in Angiosarcoma
}

\author{
MOTOHIRO CHOSOKABE ${ }^{1}$, AKIRA NOGUCHI ${ }^{1,2}$, MASAHIRO HOSHIKAWA $^{1}$, \\ MIKIO MASUZAWA ${ }^{3}$ and MASAYUKI TAKAGI ${ }^{1}$ \\ ${ }^{1}$ Department of Pathology, St. Marianna University School of Medicine, Kawasaki, Japan; \\ ${ }^{2}$ Department of Diagnostic Pathology, Graduate School of Medicine and \\ Pharmaceutical Sciences, University of Toyama, Toyama, Japan; \\ ${ }^{3}$ Department of Molecular Diagnostics, School of Allied Health Sciences, Kitasato University, Kanagawa, Japan
}

\begin{abstract}
Background/Aim: Angiosarcoma is a rare and aggressive soft tissue sarcoma with poor prognosis. Chemotherapy and radiotherapy do not improve the prognosis. SIRT1, a class III histone deacetylase, is up-regulated in many malignant tumours. This study aimed at exploring the role of SIRTl in angiosarcoma. Materials and Methods: The effect of suppressing SIRT1 expression with siRNA on the proliferation and invasion ability of ISO-HAS-B angiosarcoma cells was investigated. Additionally, SIRT1 expression in tissues from surgical specimens was immunohistochemically evaluated and compared to that from benign tumours. Results: Suppression of SIRT1 expression by siRNA resulted in the down-regulation of cell growth, proliferation, migration, and invasion. An immunohistochemical analysis disclosed that SIRT1 expression in angiosarcoma was stronger than that in haemangioma. Conclusion: SIRT1 may be involved in the invasive proliferation and malignant transformation of angiosarcoma, and may be considered a future target for angiosarcoma therapy.
\end{abstract}

Most soft tissue tumours are benign, and soft tissue sarcomas are very rare. Benign tumours are over 100 times more prevalent than malignant sarcomas (1). Angiosarcoma, a rare soft tissue tumour that accounts for approximately $1 \%$ of adult soft-tissue sarcomas, is a very aggressive endothelial neoplasm of blood vessels or lymphatic vessels (2-4). Histopathological identification of angiosarcoma poses a challenge to pathologists, because of its pathological features

This article is freely accessible online.

Correspondence to: Motohiro Chosokabe, MD, Department of Pathology, St. Marianna University School of Medicine, 2-16-1, Sugao, Miyamae-Ku, Kawasaki 216-8511, Japan. Tel: +81 449778111, e-mail: m2oyama@marianna-u.ac.jp

Key Words: SIRT1, angiosarcoma, cell proliferation. being very similar on occasion to those of other benign vascular tumours, such as haemangioma (5). Angiosarcoma is a very aggressive tumour, and therefore, the prognosis is poor. For localized and resectable tumours, surgical resection followed by adjuvant radiotherapy is the primary treatment choice. By contrast, for progressive cases, as well as for cases that are non-resectable owing to metastasis, chemotherapy is the treatment of choice (6). Weekly treatment with paclitaxel and doxorubicin is used as first- and second-line therapy (7). With these treatments, the median overall survival time is assumed to be approximately 8 to 12 months $(8,9)$. However, the incidence of angiosarcoma is less frequent than that of other malignant tumours, and knowledge related to chemotherapy is insufficient.

Sirtuin 1 (SIRT1) is the mammalian ortholog of Sir2 (silencing information regulator 2), a $\mathrm{NAD}^{+}$-dependent histone deacetylase (class III histone deacetylase, HDAC), which is a key factor regulating lifespan in yeasts and nematodes $(10,11)$. SIRT1 is associated with histone deacetylation, epigenetic silencing, suppression of rRNA recombination, and regulation of the cell cycle and longevity (12-14). Reportedly, it is associated with aging, metabolism, longevity, and response to stress $(10,11)$.

SIRT1 is known for various functions, but is not well characterized. However, according to reports, SIRT1 expression has been found to be up-regulated in several malignant tumours including breast, stomach, and prostate cancer (15-17). Based on such evidence, SIRT1 expression and accompanying deacetylation activity appear to play an oncogenic role by reducing the function of tumour suppressor genes such as p53, KU70, and the FOXO family proteins (18). In cancer cells, SIRT1 plays the role of a promoter of hypermethylated tumour suppression genes, thus contributing to their transcriptional inactivity (19). However, it also plays a role in tumour suppression, by maintaining genomic stability through regulation of chromatin structure and DNA repair action (20). 
As described above, most studies on SIRT1 have been conducted using epithelial tumours, and only a few reports describing its role in soft tissue tumours, including angiosarcoma, are available (21). Moreover, no studies examining the role of SIRT1 in angiosarcoma, using cultured cells, were found.

The objective of the current study was to determine the function of SIRT1 in angiosarcoma, by evaluating the effect of siRNA-induced SIRT1 suppression on the proliferation, migration, and invasion ability of angiosarcoma cells (ISOHAS-B). In addition, immunohistochemical analysis was conducted using tissues from clinical specimens with angiosarcoma and haemangioma. This is the first report to describe SIRT1's function in angiosarcoma.

\section{Materials and Methods}

Cell culture. ISO-HAS-B, a human angiosarcoma cell line, was obtained from the Cell Resource Center for Biomedical Research, Institute of Development, Aging and Cancer, Tohoku University. This cell line has been established from the tumour tissues of a human angiosarcoma arising on the scalp (22). The cell line was cultured in Dulbecco's Modified Eagle's medium (DMEM) (Gibco; Thermo Fisher Scientific, Inc., Waltham, MA, USA) supplemented with $10 \%$ foetal bovine serum (FBS; Equitech-Bio, Kerrville, TX, USA) at $37^{\circ} \mathrm{C}$ in a humidified atmosphere containing $95 \%$ air and $5 \% \mathrm{CO}_{2}$.

siRNA transfection. ISO-HAS-B cells were grown to $40 \%$ confluence in 6-well-plates prior to transfection with unconjugated control siRNA or SirT1 siRNA (Cell Signalling Technology, Danvers, MA, USA) using Lipofectamine ${ }^{\circledR}$ RNAiMAX Reagent (Thermo Fisher Scientific, Waltham, MA, USA), according to the manufacturer's protocol.

Western blotting. Protein was extracted from the cells using radioimmune precipitation assay (RIPA) buffer $(20 \mathrm{mM}$ Tris- $\mathrm{HCl}$ (pH 8), 137 mM NaCl, 2 mM EDTA, 2 mM EGTA, 1\% NP-40, $0.1 \%$ SDS, $0.5 \%$ sodiumu deoxycholate, $1 \mathrm{mM}$ DTT, $5 \mathrm{mM}$ $\mathrm{Na}_{3} \mathrm{VO}_{4}, 10 \mathrm{mM} \mathrm{NaF}, 10 \%$ glycerol), $48 \mathrm{~h}$ after transfection with control or SirT1 siRNA. Protein sample concentrations were measured using a TaKaRa BCA Protein Assay Kit (Takara Bio Inc., Japan). Proteins were separated by SDS-PAGE with Criterion ${ }^{\mathrm{TM}}$ TGX $^{\text {TM }}$ Precast Gel (Biorad Laboratories, Hercules, CA, USA) and transferred to nitrocellulose membranes. Membranes were blocked using an Amersham ECL Prime Blocking Agent (GE Healthcare Life Sciences, Chalfont, UK) and sequentially incubated with primary antibody and secondary antibody. The primary antibody was against SIRT1 (rabbit monoclonal, E104, Abcam, Cambridge, MA, USA, 1:500 dilution). Proteins were visualized using an enhanced chemiluminescent ECL western blot substrate (Amersham ECL Prime Western Blotting Detection Reagent; GE Healthcare Life Sciences) and scanned with an image analyser LAS-3000 (GE Healthcare Life Sciences).

Wound healing assay. Cells were seeded on 6 -well plates at $1.5 \times 10^{5}$ cells/well and supplemented with medium. Twelve hours later, transfection was performed with a control or SirT1 siRNA. Twenty-

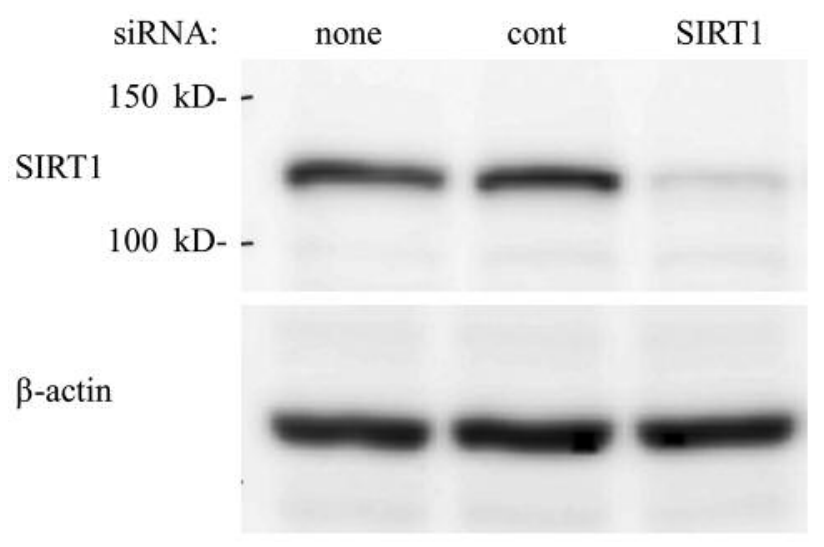

Figure 1. ISO-HAS-B cells transfected with siRNA. Protein expression levels of SIRT1 in ISO-HAS-B cells were evaluated by western blotting $24 \mathrm{~h}$ post-transfection, and $\beta$-actin was used as an internal control.

four hours following seeding, an artificial wound was created in the confluent cell monolayer. Images were immediately captured at $0 \mathrm{~h}$, and cells were incubated in DMEM with $1 \%$ FCS. Both cell growth and closing of the wound were observed and captured at $12 \mathrm{~h}$ and $24 \mathrm{~h}$. The procedure was performed in triplicate and repeated thrice.

Cell growth assay. Cell growth was determined by WST-8 (2-(2methoxy-4-nitrophenyl)-3-(4-nitrophenyl)-5-(2,4-disulfophenyl)-2Htetrazolium, monosodium salt; Cell Counting kit-8; Dojindo, Kumamoto, Japan). Cells transfected with the control or SirT1 siRNA were grown in DMEM with $10 \%$ FCS resulting in cell suspensions of 50,000 cells $/ \mathrm{ml}$. One hundred microliters each of the cell suspensions and blank (DMEM with $10 \%$ FCS only) were placed in each well of a 96-well plate and incubated for $24 \mathrm{~h}$. At each time point, $10 \mu \mathrm{l}$ of Cell Counting Kit- 8 solution was added followed by incubation for $2 \mathrm{~h}$ at $37^{\circ} \mathrm{C}$. Absorbance following each transfection at $24 \mathrm{~h}, 48 \mathrm{~h}$, and $72 \mathrm{~h}$ was recorded on a microplatereader at $450 \mathrm{~nm}$. The tests were performed in triplicate and repeated thrice.

Cell migration and invasion assay. A two-chamber migration kit (pore size, $8 \mu \mathrm{m}$ ) was used to conduct cell migration and invasion assays (CytoSelect ${ }^{\mathrm{TM}}$ 24- well cell migration and invasion assay ( 8 $\mu \mathrm{m}$, colorimetric format) Cell Biolabs, San Diego, CA, USA).

The migration assay was performed as follows. Angiosarcoma cells (ISO-HAS-B) transfected with the control or SirT1 siRNA were seeded with serum-free medium in the upper migration chamber $\left(0.3 \times 10^{6}\right.$ cells/chamber $)$, whereas DMEM with $10 \%$ FCS was added to the lower chamber. Following a $24 \mathrm{~h}$ incubation period at $37^{\circ} \mathrm{C}$, cells on the upper surface of the membrane of the upper chamber were removed with a cotton swab, and migratory cells, which remained on the lower surface of the membrane, were fixed with $4 \%$ paraformaldehyde, stained with $0.2 \%$ crystal violet, photographed, and counted in 5 random fields under a microscope.

For the invasion assay, the angiosarcoma cells (ISO-HAS-B) transfected with the control or SIRT1 siRNA were cultured for $24 \mathrm{~h}$ and suspended. The basement membrane layer was rehydrated 
A
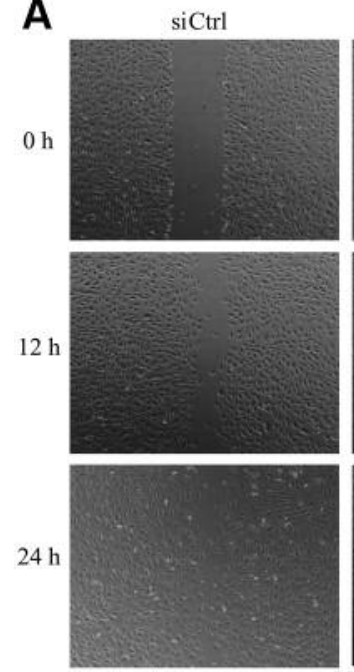

si SIRTI
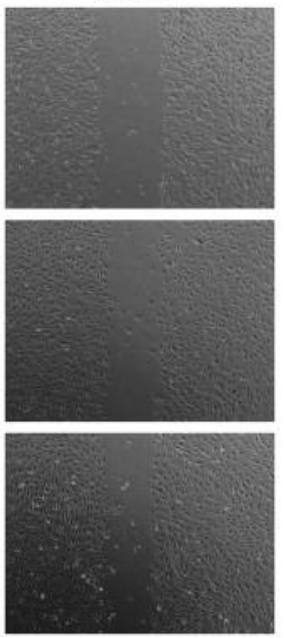

B

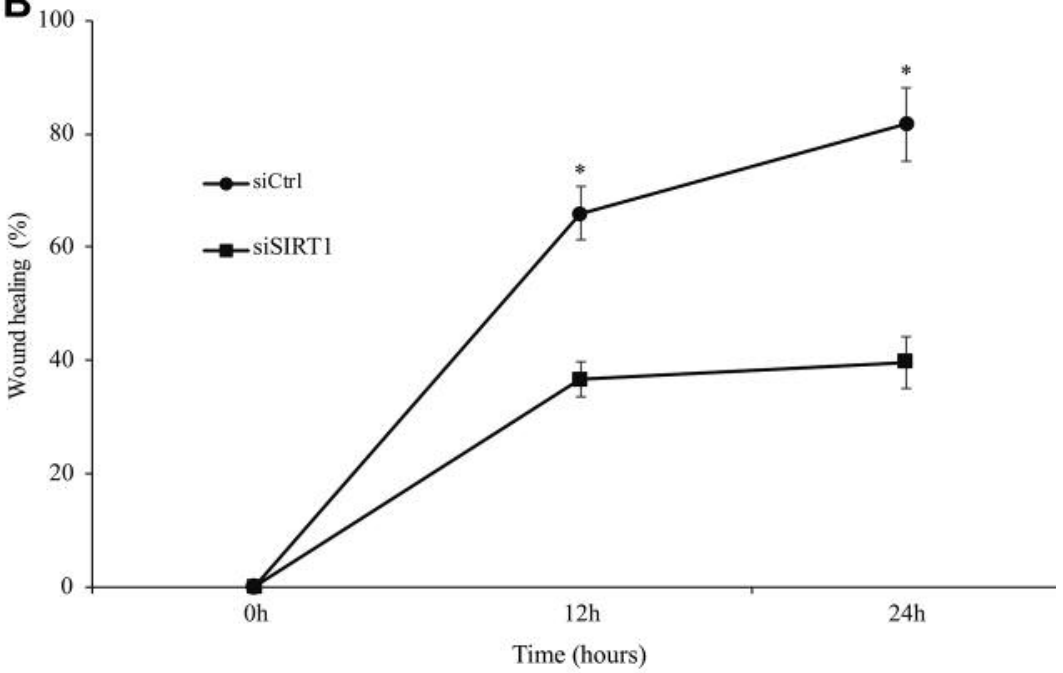

Figure 2. Delayed wound closure due to SIRT1 silencing. (A) A wound was created at the confluent monolayer of cells using a $100 \mu \mathrm{ll}$ yellow pipette tip. A subsequent wound healing assay demonstrated a significant delay in wound closure following SIRT1 expression knock down. (B) Data are presented as mean \pm standard deviation. ${ }^{*} p<0.05$, compared with the control (siCtrl).

before the migration assay. Following rehydration, transfected cells were seeded in a serum-free medium in the upper migration chamber $\left(0.3 \times 10^{6}\right.$ cells/chamber $)$ whereas DMEM with $10 \%$ FCS was added to the lower chamber. Following $24 \mathrm{~h}$ of incubation at $37^{\circ} \mathrm{C}$, cells on the upper surface of the membrane in the upper chamber were removed with a cotton swab, and invasion cells, which remained on the lower surface of the membrane, were fixed with $4 \%$ paraformaldehyde, stained with $0.2 \%$ crystal violet, photographed, and counted in five random fields under a microscope. Each migration and invasion insert was transferred into an empty well, $200 \mu \mathrm{l}$ per well of Extraction Solution (included in kit) was added, and samples were incubated for $10 \mathrm{~min}$ on an orbital shaker. Next, $100 \mu \mathrm{l}$ from each sample was transferred to a 96-well microtiter plate and OD measured at $560 \mathrm{~nm}$ in a plate reader.

Immunohistochemical analysis. Immunohistochemical analysis of SIRT1 expression was conducted using clinical specimens. Ten specimens were collected from cases diagnosed as angiosarcoma at St. Marianna University Hospital, from Jan 1, 1980 to June 30, 2018. For comparison with benign disease, 10 specimens of haemangioma were also collected. All specimens were reviewed and confirmed as angiosarcoma specimens by 3 pathologists (M.C., A.N., and M.H.).

All tissues were fixed in $10 \%$ neutralized formaldehyde and embedded in paraffin and sectioned into $4 \mu \mathrm{m}$ thick sections. These sections were dewaxed with xylene and rehydrated in ethanol. The sections subjected to antigen retrieval by heating in that targetretrieval citrate solution pH 9.0 (Target Retrieval Solution, DAKO) for $50 \mathrm{~min}$ in a water bath at $95^{\circ} \mathrm{C}$ and incubated overnight at $4^{\circ} \mathrm{C}$ with the primary antibody against SIRT1 (mouse monoclonal, B-7, Santa Cruz, CA, USA, 1:100 dilution). In order to evaluate SIRT1 protein expression using the Allred score (23), the intensity score was divided in four categories ranging from $0-3$, and the portion with SIRT1-positive cells was subdivided into categories ranging from 0-5. Both values were added to obtain the Allred scores ranging from $0-8$. Allred scores were independently judged by three pathologists and only unanimous decisions were allowed.

Ethics. The immunohistochemical analysis study was conducted in full compliance with the Helsinki Declaration and approved as a retrospective study by the ethics committee of St. Marianna University School of Medicine (No. 4069). Informed consent was obtained in accordance with the Helsinki Declaration.

Statistical analyses. Results of wound healing, and migration and invasion assays were analyzed with the student's $t$-test. In order to compare the staining properties of SIRT1 between angiosarcoma and haemangioma, their Allred scores were tested by the Wilcoxon rank sum test. All statistical analyses were conducted using the $\mathrm{R}$ statistical software package (revision 3.5.1, available as a free download from http://www.r-project.org). Statistical significance was set at $p<0.05$.

\section{Results}

Knockdown of SIRT1 by siRNA in ISO-HAS-B cells. In order to investigate normal expression and biological function of SIRT1 in ISO-HAS-B cells, SIRT1 expression levels were analyzed by western blotting. Protein expression levels of SIRT1 were markedly decreased $24 \mathrm{~h}$ following siRNA transfection (Figure 1). Therefore, all subsequent experiments were performed using cells transfected with SIRT1 or control siRNA.

Wound healing assay data demonstrated a remarkable delay in wound healing following transfection with SIRT1 


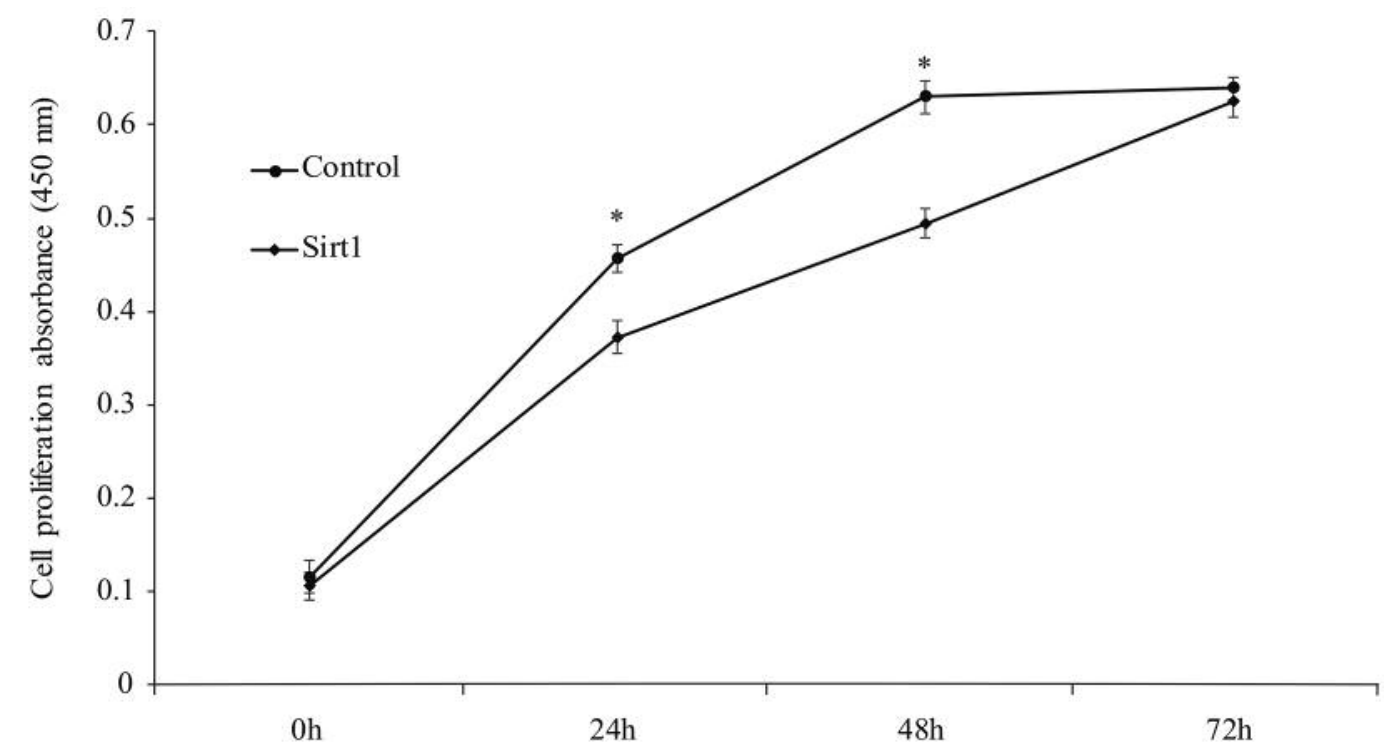

Figure 3. SIRT1 mediated regulation of ISO-HAS-B cells. A Cell Counting kit 8 cell proliferation assay was performed to measure the proliferation ability of ISO-HAS-B cells. Data are presented as mean \pm standard deviation in triplicate. ${ }^{*} p<0.05$, compared to the control.

siRNA. Wound healing was significantly slower in ISOHAS-B cells with knocked down SIRT1 (Figure 2).

The cell proliferation assay indicated that SIRT1 knockdown regulated ISO-HAS-B cell proliferation. Significant differences in cell proliferation were seen following $24 \mathrm{~h}$ and $48 \mathrm{~h}$. At $72 \mathrm{~h}$, the cell proliferation was almost similar (Figure 3).

In the cell migration and invasion assay, knockdown of SIRT1 by siRNA in ISO-HAS-B cells inhibited cell migration and invasion. Invasion is an important process in the progression of malignant tumour metastasis. The ability of ISOHAS-B cells to invade the Matrigel $^{\mathrm{TM}}$, and the artificial extracellular matrix (ECM), was measured following transfection with SIRT1 and control siRNA. Knockdown of SIRT1 expression resulted in a $24.3 \%$ reduction in cell migration and a $12.9 \%$ reduction in cell invasion (Figure 4). Statistical analysis showed that significantly fewer cells $(p<0.05)$ passed through the polycarbonate membrane inserts ( $8 \mu \mathrm{m}$ pore) and the filters coated with the artificial extracellular matrix. This indicated that the migratory and invasive potential of ISO-HAS-B cells was regulated by SIRT1 knockdown.

Immunohistochemical analysis. Immunohistochemical staining results of 10 angiosarcoma and haemangioma specimens (Table I), as well as the typical staining results for SIRT1 in angiosarcoma and haemangioma specimens are shown in Figure 5. Angiosarcoma showed strong positive staining. However, the haemangioma was diffusely stained, and the staining intensity was weak. Moreover, neither specimen showed a completely negative result.
Immunohistochemical staining was evaluated using the Allred score. Average values of the SIRT1 positive cell ratio, estimated by three pathologists, were high for both angiosarcoma and haemangioma specimens. However, the staining intensity of angiosarcoma specimens was higher than that of haemangioma. As a result, the Allred score was higher for angiosarcoma specimens than for haemangioma specimens.

\section{Discussion}

Molecular mechanisms underlying the regulation of SIRT1 activation have been recently reported. In the nutritiondeficient state, FoxO3A translocates into the cell nucleus and causes dissociation of p53 from the promoter region of SIRT1 (25). As p53 suppresses SIRT1 expression, dissociation of p53 by FoxO3A increases translation of SIRT1 gene (26). A study using breast cancer cells reported that hypermethylated in cancer 1 (HIC1), which is associated with cancer suppression, binds to the enhancer region of SIRT1 and suppresses its transcription (26). In cancer cells, methylation of the promoter of $\mathrm{HICl}$ results in decreased expression of the protein and reduced binding to SIRT1 promoter. As a result, SIRT1 expression may increase, potentially affecting tumour growth. Since SIRT1 deacetylates p53 and reduces its activity, it will also be resistant to p53-dependent cell death. In contrast, SIRT1 is also regulated by the transcription factor E2F1 (27). E2F1 is a cell death inducer, and it might interact with SIRT1 following DNA damage, thereby promoting cell death. 

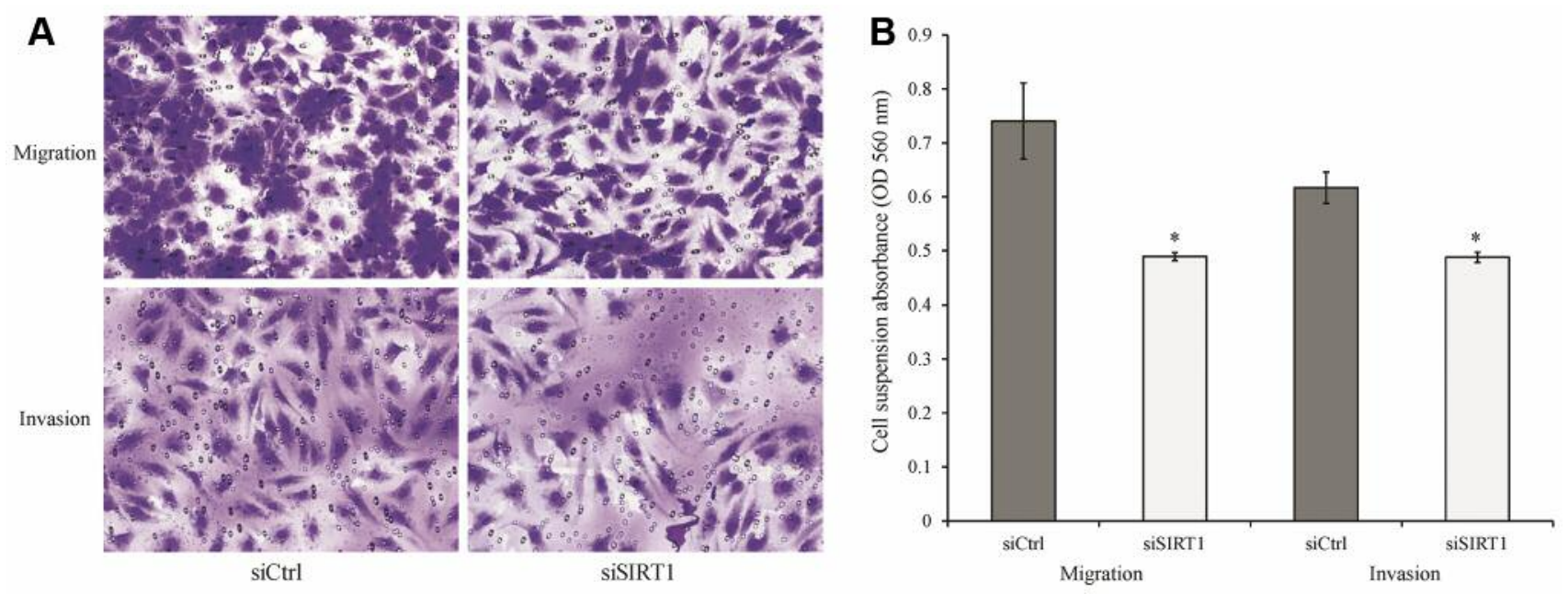

Figure 4. Suppression of migration and invasion of ISO-HAS-B cells following knockdown of SIRT1. (A) Representative fields of migratory and invasion cells on the membrane. (B) The average quantified cells at OD $560 \mathrm{~nm}$ after counting the number of migratory and invasion cells per field. $* p<0.05$, compared with the control.

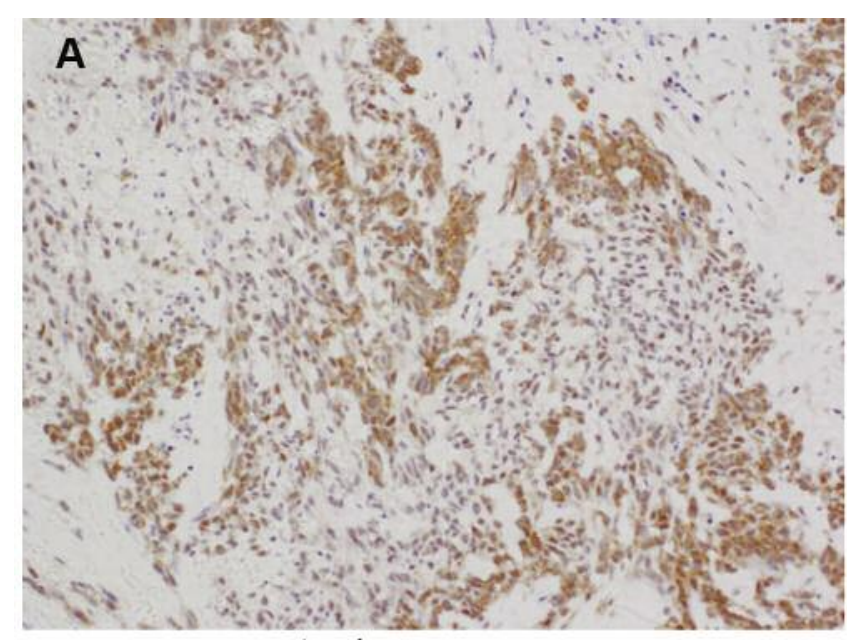

Angiosarcoma

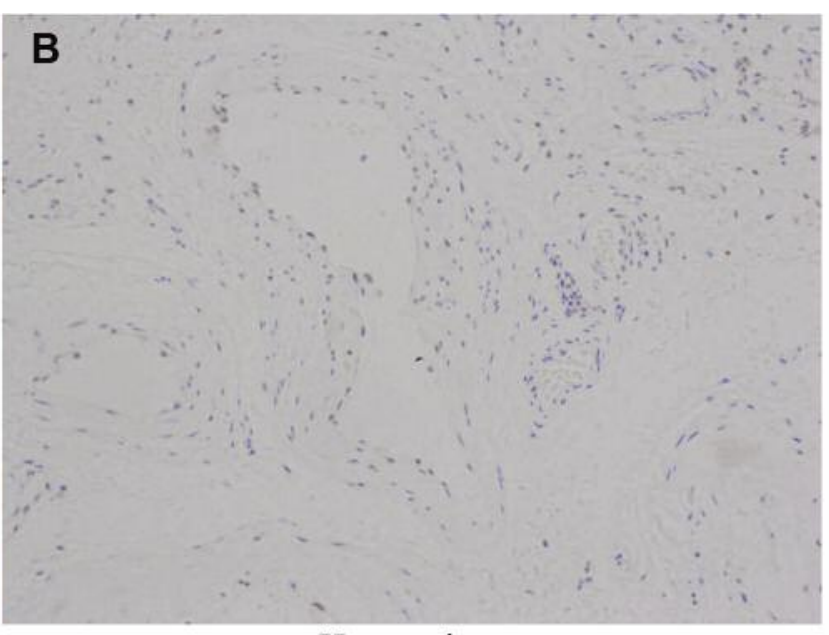

Hemangioma

Figure 5. Immunohistochemical staining showing stronger SIRT1 expression in angiosarcoma than haemangioma. SIRT1 expression in (A) angiosarcoma and (B) haemangioma.

As described above, mechanisms regulating the function of SIRT1 are complicated, and its precise role in malignant tumours remains unclear. In recent years, many studies have been conducted on the association between SIRT1 and malignant tumours. Jang et al. reported that SIRT1 was positive in $74 \%$ of diffuse large B-cell lymphoma (DLBCL) cases (77/104), according to tissue microarray analyses (28). Noguchi et al. found a correlation between the degree of gastric cancer progression and SIRT1 expression, in an immunohistochemical study of 557 gastric cancer cases (29).

Sung et al. reported that SIRT1 was strongly expressed at the protein level in the tumour tissues from 28 breast cancer cases, but not at the transcription level (30). Zhao et al. reported that there was high SIRT1 mRNA and protein expression in pancreatic cancer, which correlated with TNM classification and lymph node metastasis (31). SIRT1 expression in soft tissue tumours has been described in several reports $(32,33)$. Jung et al. examined the expression 
Table I. Clinical data and Allred scores of angiosarcoma and haemangioma cases. Samples of angiosarcoma were significantly more susceptible to SIRT1 than those of haemangioma $(p<0.05)$.

\begin{tabular}{|c|c|c|c|c|c|c|c|c|c|}
\hline Angiosarcoma & Origin & Age & Gender & Allred score & Haemangioma & Origin & Age & Gender & Allred score \\
\hline Case 1 & Liver & 50 & M & 7.3 & Case 1 & Skin & 3 & $\mathrm{~F}$ & 5.3 \\
\hline Case 2 & Heart & 48 & M & 6.7 & Case 2 & Kidney & 38 & $\mathrm{~F}$ & 5.3 \\
\hline Case 3 & Kidney & 79 & $\mathrm{M}$ & 8.0 & Case 3 & Skin & 4 & $\mathrm{~F}$ & 5.7 \\
\hline Case 4 & Skin & 84 & $\mathrm{M}$ & 5.3 & Case 4 & Skin & 16 & $\mathrm{~F}$ & 5.0 \\
\hline Case 5 & Breast & 33 & $\mathrm{~F}$ & 7.0 & Case 5 & Liver & 88 & M & 4.0 \\
\hline Case 6 & Liver & 55 & $\mathrm{~F}$ & 5.7 & Case 6 & Skin & 19 & $\mathrm{~F}$ & 6.3 \\
\hline Case 7 & Breast & 80 & $\mathrm{M}$ & 6.0 & Case 7 & Liver & 35 & $\mathrm{M}$ & 5.0 \\
\hline Case 8 & Skin & 81 & $\mathrm{~F}$ & 8.0 & Case 8 & Skin & 15 & $\mathrm{~F}$ & 4.3 \\
\hline Case 9 & Skin & 76 & $\mathrm{~F}$ & 7.0 & Case 9 & Liver & 51 & $\mathrm{~F}$ & 5.0 \\
\hline Case 10 & Heart & 66 & M & 7.3 & Case 10 & Skin & 80 & M & 5.0 \\
\hline Average & & & & 6.8 & Average & & & & 5.1 \\
\hline
\end{tabular}

The value of the Allred score is the average of the results from three pathologists.

of SIRT1 in soft tissue sarcoma via immunohistochemical staining. In this study, expression was evident in all cases with angiosarcoma $(5 / 5$ or $100 \%)$, whereas such examples of expression were not observed in dedifferentiated liposarcoma. Therefore, SIRT1 expression in sarcoma may not necessarily be constant. They further postulated the possibility of SIRT1 expression being associated with poor prognosis in sarcoma (21).

In the present study, all clinical specimens showed a strong association between SIRT1 expression and pathogenesis of angiosarcoma. This result is consistent with those of previous reports. Thus, SIRT1 may be involved in the tumorigenesis and proliferation of not only epithelial tumours but also soft tissue tumours.

Only a few angiosarcoma cultured cell lines can be used for experiments, to our knowledge, there are no reports on the in vitro expression of SIRT1. We examined the effect of SIRT1 inhibition on the proliferative activity and invasive ability of the cultured cell line ISO-HAS-B, established using human scalp angiosarcoma $(22,34)$. Western blotting confirmed that SIRT1 was endogenously expressed by ISOHAS-B. Furthermore, in order to examine the role of SIRT1, SIRT1 expression was knocked-down using siRNA, and the results of wound healing and proliferative assays demonstrated that cell proliferation was inhibited.

Results of the migration assay confirmed that cell migration ability was reduced, and invasion assay results demonstrated that invasion activity was also decreased. Ning et al. reported that proliferation was suppressed because of suppression of SIRT1 expression in the cultured cells of osteosarcoma, which is believed to be relatively similar to angiosarcoma. In a study using clinical specimens, SIRT1 was found to be overexpressed in osteosarcoma compared to normal tissue, where the extent of expression was correlated with the risk of metastasis (35). Furthermore, in nude mice, lung metastasis of an osteosarcoma metastasis model was suppressed by knocking-down SIRT1 (35).

The current study indicated that SIRT1 promoted tumour growth in angiosarcoma. However, several studies reported that SIRT1 expression may be associated with tumour suppression. It was reported that SIRT1 may be strongly expressed in early colorectal cancer, but there are reports of many advanced cancers showing weak SIRT1 expression (36). Firestein et al. considered the weak expression to be due to the involvement of SIRT1 in deacetylation of $\beta$-catenin (37). As described above, SIRT1 has various functions, and it is still unclear whether it acts to promote malignant tumours or to suppress them. Depending on the type of tumour, the function of SIRT1 may be different. Our study indicated that SIRT1 promoted proliferation and invasion of angiosarcoma. Therefore, SIRT1 may warrant further studies in order to assess its potential as a biomarker for predicting the growth and infiltration of angiosarcoma. Our findings also suggest the possibility that SIRT1 is a potential target in the treatment of angiosarcoma.

\section{Conclusion}

SIRT1 is known to play a variety of roles in the pathogenesis of malignant tumours. SIRT1 is strongly expressed in angiosarcoma, where it may promote tumour growth, migration, and invasion. SIRT1 may be a therapeutic target for angiosarcoma.

\section{Conflicts of Interest}

The Authors declare no conflicts of interest regarding this study. 


\section{Authors' Contributions}

Study concepts: MC. Study design: MC. Data acquisition: MC. Data analysis and interpretation: MC, AN, MH. Statistical analysis: MC. Manuscript preparation: MC. Manuscript editing: MC. Manuscript review: MC, NA, MH, MM, MT. All Authors read and approved the final manuscript.

\section{Acknowledgements}

This work was supported by the Department of Pathology of St. Marianna University School of Medicine. The Authors thank Hiromi Aoki, Atsushi Goda, Manabu Kubota, and Shigeko Ohnuma for technical assistance.

\section{References}

1 Fletcher CDM, Bridge JA, Hogendoorn PCW and Mertens F: WHO classification of tumours of soft tissue and bone. Lyon, France: IARC Press, 2013.

2 Torosian MH, Friedrich C, Godblod J, Hadju SI and Brennan M: Soft-tissue sarcoma: initial characteristics and prognostic factors in patients with or without metastatic disease. Semin Surg Oncol 4: 13-19, 1988. PMID: 3353619

3 Coindre JM, Terrier P, Guillou L, Le Doussal V, Collin F, Ranchère D, Sastre X, Vilain MO, Bonichon F and N'Guyen Bui $B$ : Predictive value of grade for metastasis development in the main histologic types of adult soft tissue sarcomas. A study of 1240 patients from the French Federation of Cancer Centers Sarcoma Group. Cancer 91: 1914-1926, 2001. PMID: 11346874

4 Penel N, Grosjean J, Robin YM, Vanseymortier L, Clisant S and Adenis A: Frequency of certain established risk factors in soft tissue sarcomas in adult: a prospective descriptive study of 658 cases. Sarcoma 2008: 459386, 2008. PMID: 18497869, DOI: $10.1155 / 2008 / 459386$

5 Ohsawa M, Naka N, Tomita Y, Kawamori D, Kanno H and Aozasa K: Use of immunohistochemical procedures in diagnosing angiosarcoma. Evaluation of 98 cases. Cancer 75: 2867-2874, 1995. PMID: 7773935

6 Penel N, Marréaud S, Robin YM and Hohenberger P: Angiosarcoma: state of the art and perspectives. Crit Rev Oncol Hematol 2: 257-263, 2011. PMID: 21055965, DOI: 10.1016/ j.critrevonc.2010.10.007

7 Penel N, Bui BN, Bay JO, Cupissol D, Ray-Coquard I, PipernoNeumann S, Kerbrat P, Fournier C, Taieb S, Jimenez M, Isambert $\mathrm{N}$, Peyrade $\mathrm{F}$, Chevreau $\mathrm{C}$, Bompas $\mathrm{E}$, Brain EG and Blay JY: Phase II trial of weekly paclitaxel for unresectable angiosarcoma: the AngioTax study. J Clin Oncol 26: 5269-5274, 2008. PMID: 18809609, DOI: 10.1200/JCO.2008.17.3146

8 Fayette J, Martin E, Piperno-Neumann S, Le Cesne A, Robert $\mathrm{C}$, Bonvalot $\mathrm{S}$, Ranchère $\mathrm{D}$, Pouillart $\mathrm{P}$, Coindre $\mathrm{JM}$ and Blay JY: Angiosarcomas, a heterogeneous group of sarcomas with specific behaviour depending on primary site: a retrospective study of 161 cases. Ann Oncol 18: 2030-2036, 2007. PMID: 17974557, DOI: 10.1093/annonc/mdm381

9 Salas S, Stock N, Stoeckle E, Kind M, Bui B and Coindre JM: Chronic lymphedema due to morbid obesity: an exceptional cause of abdominal wall angiosarcoma. Virchow Arch 453: 217219, 2008. PMID: 18560886, DOI: 10.1007/s00428-008-0623-8
10 Dali-Youcef N, Lagouge M, Froelich S, Koehl C, Schoonjans K and Auwerx J: Sirtuins: the "magnificent seven", function, metabolism and longevity. Ann Med 39: 335-345, 2007. PMID: 17701476, DOI: 10.1080/07853890701408194

11 Imai S, Johnson FB, Marciniak RA, McVey M, Park PU and Guarente L: Sir2: an NAD-dependent histone deacetylase that connects chromatin silencing, metabolism, and aging. Cold Spring Harb Symp Quant Biol 65: 297-202, 2000. PMID: 12760043

12 Cheng HL, Mostoslavsky R, Saito S, Manis JP, Gu Y, Patel P, Bronson R, Appella E, Alt FW and Chua KF: Developmental defects and p53 hyperacetylation in Sir2 homolog (SIRT1)deficient mice. Proc Natl Acad Sci USA 100: 10794-10799, 2003. PMID: 12960381, DOI: 10.1073/pnas.1934713100

13 Hisahara S, Chiba S, Matsumoto H, Tanno M, Yagi H, Shimohama S, Sato M and Horio Y: Histone deacetylase SIRT1 modulates neuronal differentiation by its nuclear translocation. Proc Natl Acad Sci USA 105: 15599-15604, 2008. PMID: 18829436, DOI: 10.1073/pnas.0800612105

14 Longo VD and Kennedy BK: Sirtuins in aging and age-related disease. Cell 126: 257-268, 2006. PMID: 16873059, DOI: 10.1016/j.cell.2006.07.002

15 Huffman DM, Grizzle WE, Bamman MM, Kim JS, Eltoum IA, Elgavish A and Nagy TR: SIRT1 is significantly elevated in mouse and human prostate cancer. Cancer Res 67: 6612-6618, 2007. PMID: 17638871, DOI: 10.1158/0008-5472.CAN-070085

16 Cha EJ, Noh SJ, Kwon KS, Kim CY, Park BH, Park HS, Lee H, Chung MJ, Kang MJ, Lee DG, Moon WS and Jang KY: Expression of DBC1 and SIRT1 is associated with poor prognosis of gastric carcinoma. Clin Cancer Res 15: 4453-4459, 2009. PMID: 19509139, DOI: 10.1158/1078-0432.CCR-08-3329

17 Ashraf N, Zino S, MacIntyre A, Kingsmore D, Payne AP, George W and Shiels PG: Altered sirtuin expression is associated with node-positive breast cancer. Br J Cancer 95: 1056-1061, 2006. PMID: 17003781, DOI: 10.1038/sj.bjc.6603384

18 Ota H, Tokunaga E, Chang K, Hikasa M, Iijima K, Eto M, Kozaki K, Akishita M, Ouchi Y and Kaneki M: Sirt1 inhibitor, sirtinol, induces senescence-like growth arrest with attenuated Ras- MAPK signaling in human cancer cells. Oncogene 25: 176185, 2006. PMID: 16170353, DOI: 10.1038/sj.onc.1209049

19 Pruitt K, Zinn RL, Ohm JE, McGarvey KM, Kang SH, Watkins DN, Herman JG and Baylin SB: Inhibition of SIRT1 reactivates silenced cancer genes without loss of promoter DNA hypermethylation. PLoS Genet 2: e40, 2006. PMID: 16596166, DOI: 10.1371/journal.pgen.0020040

20 Bosch-Presegue $\mathrm{L}$ and Vaquero A: The dual role of sirtuins in cancer. Genes Cancer 2: 648-662, 2011. PMID: 21941620, DOI: $10.1177 / 1947601911417862$

21 Kim JR, Moon YJ, Kwon KS, Bae JS, Wagle S, Yu TK, Kim KM, Park HS, Lee JH, Moon WS, Lee H, Chung MJ and Jang KY: Expression of SIRT1 and DBC1 is associated with poor prognosis of soft tissue sarcomas. PLoS One 8: e74738, 2013. PMID: 24019980, DOI: 10.1371/journal.pone.0074738

22 Masuzawa M, Fujimura T and Hamada Y: Establishment of a human hemangiosarcoma cell line (ISO-HAS). Int J Cancer 81: 305-308, 1999. PMID: 10188735

23 Allred DC, Harvey JM, Berardo M and Clark GM: Prognostic and predictive factors in breast cancer by immunohistochemical analysis. Mod Pathol 11: 155-168, 1998. PMID: 9504686 
24 Daitoku H, Sakamaki J and Fukamizu A: Regulation of FoxO transcription factors by acetylation and protein-protein interactions, Biochim Biophys Acta 1813: 1954-1960, 2011. PMID: 21396404, DOI: 10.1016/j.bbamcr.2011.03.001

25 Nemoto S, Fergusson MM and Finkel T: Nutrient availability regulates SIRT1 through a forkhead-dependent pathway. Science 306: 2105-2108, 2004. PMID: 15604409 DOI: 10.1126/ science. 1101731

26 Chen WY, Wang DH, Yen RC, Luo J, Gu W and Baylin SB: Tumor suppressor HIC1 directly regulates SIRT1 to modulate p53-dependent DNA-damage responses. Cell 123: 437-448, 2005. PMID: 16269335, DOI: 10.1016/j.cell.2005.08.011

27 Wang C, Chen L, Hou X, Li Z, Kabra N, Ma Y, Nemoto S, Finkel T, Gu W, Cress WD and Chen J: Interactions between E2F1 and SirT1 regulate apoptotic response to DNA damage. Nat Cell Biol 8: 1025-1031, 2006. PMID: 16892051, DOI: $10.1038 / \mathrm{ncb} 1468$

28 Jang KY, Hwang SH and Kwon KS: SIRT1 expression is associated with poor prognosis of diffuse large B-cell lymphoma. Am J Surg Pathol 32: 1523-1531, 2008. PMID: 18724249, DOI: 10.1097/PAS.0b013e31816b6478

29 Noguchi A, Kikuchi $K$ and Zheng H: SIRT1 expression is associated with a poor prognosis, whereas DBC1 is associated with favourable outcomes in gastric cancer. Cancer Med 3: 1553-1561, 2014. PMID: 25146318, DOI: 10.1002/cam4.310

30 Sung JY, Kim R, Kim JE and Lee J: Balance between SIRT1 and DBC1 expression is lost in breast cancer. Cancer Sci 101: 17381744, 2010. PMID: 20412117, DOI: 10.1111/j.13497006.2010.01573.x

31 Zhao G, Cui J and Zhang J: SIRT1 RNAi knockdown induces apoptosis and senescence, inhibits invasion and enhances chemosensitivity in pancreatic cancer cells. Gene Ther 18: 920928, 2011. PMID: 21677689, DOI: 10.1038/gt.2011.81
32 Tong X, Wang X, Wang C and Li L: Elevated levels of serum MiR-152 and miR-24 in uterine sarcoma: potential for inducing autophagy via SIRT1 and deacetylated LC3. Br J Biomed Sci 75: 7-12, 2018. PMID: 28929922, DOI: 10.1080/ 09674845.2017.1340225

33 Feng H, Guo P, Wang J, Xu J, Xie C and Gao F: Expression of Leptin and Sirtuin-1 is associated with poor prognosis in patients with osteosarcoma. Pathol Res Pract 212: 319-324, 2016. PMID: 26936024, DOI: 10.1016/j.prp.2016.02.002

34 Masuzawa M, Fujimura T and Tsubokawa M: Establishment of a new murine-phenotypic angiosarcoma cell line (ISOS-1), J Dermatol Sci 16: 91-98, 1998. PMID: 9459120

35 Zhang N, Xie T and Xian M: SIRT1 promotes metastasis of human osteosarcoma cells. Oncotarget 7: 79654-79669, 2016. PMID: 27793039, DOI: 10.18632/oncotarget.12916

36 Kabra N, Li Z, Chen L: SirT1 is an inhibitor of proliferation and tumor formation in colon cancer. J Biol Chem 284: 1821018217, 2009. PMID: 19433578, DOI: 10.1074/jbc.M109.000034

37 Firestein R, Blander G and Michan S: The SIRT1 deacetylase suppresses intestinal tumorigenesis and colon cancer growth. PLoS One 4: e2020, 2008. PMID: 18414679, DOI: 10.1371/ journal.pone. 0002020 